\title{
Prevalence of Subclinical Hypothyroidism in Patients with Chronic Kidney Disease
}

\author{
Chandramohan.G, DM (Nephrology) ${ }^{1}$, Srinivasaprasad.N.D, DM \\ (Nephrology) ${ }^{2}$, Mahalakshmi, MD (Biochemistry) ${ }^{3}$ Shivasomana J, MD \\ (Biochemistry) ${ }^{4}$ Edwin Fernando, DM (Nephrology) $)^{5}$, \\ ${ }^{1}$ Assistant Professor, Department Of Nephrology, Stanley Medical College, Chennai. \\ ${ }^{2}$ Assistant Professor, Department Of Nephrology, Stanley Medical College, Chennai. \\ ${ }^{3}$ Professor, Department Of Biochemistry, Stanley Medical College, Chennai. \\ ${ }^{4}$ Senior Resident, Department Of Biochemistry, Stanley Medical College, Chennai. \\ ${ }^{5}$ Professor \& Head, Department Of Nephrology, Stanley Medical College, Chennai.
}

\begin{abstract}
Background: Subclinical primary hypothyroidism is highly prevalent in the general population, especially in the elderly and females above 45yrs of age. However, the prevalence of subclinical primary hypothyroidism in persons with chronic kidney disease (CKD) not requiring dialysis is not well defined.

Aim:

1. To Study the prevalence of Subclinical Hypothyroidism in patients with CKD, and

2. To study the correlation between thyroid dysfunction and the various stages of CKD.

Materials and methods: This study was conducted in Stanley Medical College, Chennai, Tamil Nadu, India by the Department of Nephrology and Biochemistry in May 2016. Cross-sectional data from 50 healthy adult outpatients, who were consecutively referred for master health check-up considered as controls and 50 nondialytic CKD patients satisfying the study criteria considered as cases, were analyzed. Glomerular filtration rate (GFR) was estimated by the abbreviated Modification of Diet in Renal Disease equation. Pearson correlation coefficient was used to evaluate the degree of association between prevalent subclinical primary hypothyroidism and estimated GFR. Students unpaired t test was used to compare the means between two groups.

Results: Among 50 cases, 30 (60\%) had subclinical primary hypothyroidism. The prevalence of subclinical primary hypothyroidism increased from $2 \%$ at an estimated GFR $>90 \mathrm{ml} / \mathrm{min}$ per $1.73 \mathrm{~m} 2$ (controls) to $60 \%$ at an estimated GFR $<90 \mathrm{ml} / \mathrm{min}$ per $1.73 \mathrm{~m} 2(P<0.001$ for trend). The prevalence of subclinical primary hypothyroidism increased from $59 \%$ at an estimated GFR between 15 \& $89 \mathrm{ml} / \mathrm{min}$ per $1.73 \mathrm{~m} 2$ to $90 \%$ at an estimated GFR $<15 \mathrm{ml} / \mathrm{min}$ per $1.73 \mathrm{~m} 2$.

Conclusions: These findings suggest that subclinical primary hypothyroidism is a relatively common condition (60\%) among persons with CKD not requiring dialysis, and it is independently associated with progressively lower estimated GFR in a small group of patients.
\end{abstract}

\section{Back Ground}

The concept of subclinical primary hypothyroidism has emerged over the past several decades, as our ability to detect subtle changes in thyroid function tests is progressively improved $(1,2)$. Although it is recognized that patients with subclinical primary hypothyroidism may have subtle symptoms of thyroid dysfunction, the definition is purely a biochemical one, defined as elevated serum thyrotropin (TSH) levels but normal free thyroxine (FT) levels (3). Subclinical primary hypothyroidism has been recognized in several studies to be associated with markers of cardiovascular risk and cardiac impairment (4-7). Even minor deviations from serum TSH normal range might accelerate the development of atherosclerosis and have adverse effects on cardiovascular performance in the general population (4-7). Moreover, subclinical primary hypothyroidism has been identified as a strong predictor of all cause mortality in chronic dialysis patients and as a risk factor for nephropathy and cardiovascular events in type 2 diabetic patients $(8,9)$. There is, however, limited quantitative evidence regarding the prevalence of subclinical primary hypothyroidism in Indian patients at different levels of estimated glomerular filtration rate (GFR) (10). To explore this question, we have performed a cross sectional analysis of non dialytic chronic kidney disease patients as cases and healthy adults attending master health check up as controls with the purpose of estimating the prevalence of subclinical primary hypothyroidism at different levels of kidney functions. 


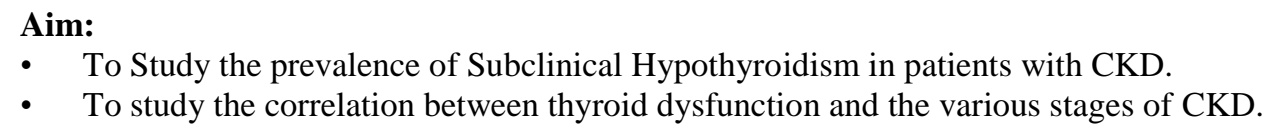

\section{Materials And Methods}

This study was conducted in Stanley Medical College, Chennai, Tamil Nadu, India by the Department of Nephrology and Biochemistry May 2016. Cross-sectional data from 50 healthy adult outpatients, who were consecutively referred for master health check-up considered as controls and 50 nondialytic CKD patients satisfying the study criteria considered as cases, were analyzed. Patients aged $>20$ years, with duration of illness more than 6 months were included in the study. Those who had visible goitre, obvious features of hypothyroidism, already diagnosed thyroid disorders on treatment and those taking drugs like estrogen, steroids, sulphonyl ureas and beta blockers were excluded. All participants gave their informed consent. The local ethics committee approved the study protocol. Venous blood from all participants was routinely collected in the morning on fasting subjects, and serum urea, creatinine, total protein concentrations were assayed by enzymatic procedures on Beckman Coulter AU 480 autoanalyser after calibration using IDMS reference calibrator (for creatinine), according to manufacturer's specifications and employing proprietary reagents. Serum TSH and FT4 concentrations were quantified by Sandwich type of Immunoenzymometric Assay and Competitive enzyme Immunoassay. Functional sensitivity for TSH and FT was quoted by the manufacturer as $0.004 \mathrm{mIU} / \mathrm{L}$ and 0.3 $\mathrm{ng} / \mathrm{dl}$, respectively. Reference values in our laboratory were 0.4 to $4.2 \mathrm{mIU} / \mathrm{L}$ for TSH and 0.8 to $1.8 \mathrm{ng} / \mathrm{dl}$ for FT4, respectively. No FT3 and serum thyroid peroxidase antibody measurements were done.

Kidney function was calculated by using the formula developed and validated in the Modification of Diet in Renal Disease study. The Modification of Diet in Renal Disease formula was as follows: estimated GFR $=175.0 \times($ serum creatinine $) \times($ age $) \times 1.212$ (if black $) \times 0.742$ (if female $)(11)$.

\section{Statistical Analysis}

Results of clinical and hormonal assessment of thyroid dysfunction obtained in patients with chronic kidney disease were compared with those of the control group by statistical analysis using Excel software. Students unpaired' $t$ ' test is used to compare the means between two independent groups. $F$ test is applied between the study variables to know whether ' $t$ ' test can be applied to study the parameters and also which type of ' $t$ ' test -either equal variance or separate variance unpaired ' $t$ ' test can be applied in this study. Pearson coefficient of correlation is used to estimate the degree of association between two quantitative variables. A pvalue of $<0.001$ will be considered as statistically significant.

\section{In Controls}

Table.1 Baseline Characteristics Of The Study Population

Male to female ratio was $1.17(27 / 23)$. The mean values of estimated GFR, serum TSH, and FT4 concentrations were $106.8 \pm 11.35 \mathrm{ml} / \mathrm{min}$ per $1.73 \mathrm{~m} 2$ (range $92-120$ ), $2.020 \pm 1.16 \mathrm{mIU} / \mathrm{L}$, and $1.15 \pm 0.38$ $\mathrm{ng} / \mathrm{dl}$, respectively. Most participants $(n=49,98 \%)$ had serum thyroid function test results within the reference range (i.e., TSH values ranging from 0.4 to $4.2 \mathrm{mIU} / \mathrm{L}$ with normal FT4 levels), whereas $2 \%(n=1,1$ females) had subclinical biochemical hypothyroidism (i.e., TSH >4.2 mIU/L with normal FT4 levels). (Table 1)

\section{In Cases}

Male to female ratio was 1.63(31/19). The mean values of estimated GFR, serum TSH, and FT4 concentrations were $22.7 \pm 7.85 \mathrm{ml} / \mathrm{min}$ per $1.73 \mathrm{~m} 2,6.74 \pm 6.12 \mathrm{mIU} / \mathrm{L}$, and $1.38 \pm 0.32 \mathrm{ng} / \mathrm{dl}$, respectively. Most participants $(n=33,66 \%)$ had abnormal serum thyroid function test results. $30(60 \%)$ had subclinical hypothyroidism (i.e., TSH values > $4.2 \mathrm{mIU} / \mathrm{L}$ with normal FT4 levels), whereas $4 \%(n=2) \mathrm{had}$ hypothyroidism [i.e., TSH $>4.2 \mathrm{mIU} / \mathrm{L}$ with low FT4 $(<0.8 \mathrm{ng} / \mathrm{ml})$ levels] and 1 patient had subclinical hyperthyroidism (i.e., TSH values $<0.4 \mathrm{mIU} / \mathrm{L}$ with normal FT4 levels) (Table 1).

Participants with subclinical primary hypothyroidism were likely to be older and had lower estimated GFR levels than their counterparts with no subclinical hypothyroidism. As expected, serum TSH levels were higher and FT levels were lower in the hypothyroid group. No significant difference was found in gender distribution between the groups. The prevalence of participants with estimated GFR $<60 \mathrm{ml} / \mathrm{min}$ per $1.73 \mathrm{~m}$ was remarkably greater among those with subclinical hypothyroidism than among those with no hypothyroidism. As shown in Table 2, the prevalence of subclinical primary hypothyroidism was increased in persons with progressively lower kidney function, ranging from $2 \%$ for persons with estimated GFR $\geq 90 \mathrm{ml} / \mathrm{min}$ per $1.73 \mathrm{~m} 2$ to $66.8 \%$ in persons with estimated GFR below $60 \mathrm{ml} / \mathrm{min}$ per $1.73 \mathrm{~m} 2$ (Table 2). Notably, when estimated GFR was subdivided into deciles instead of widely accepted diagnostic categories for CKD stages, the prevalence of subclinical primary hypothyroidism was markedly increased among those in the last decile of estimated GFR (mean estimated GFR, $8.7 \mathrm{ml} / \mathrm{min}$ per $1.73 \mathrm{~m} 2$ ) compared with those in the highest estimated GFR decile (mean 
estimated GFR, $106.8 \pm 11.35 \mathrm{ml} / \mathrm{min}$ per $1.73 \mathrm{~m} 2$ ). Similarly, there was a graded significant decrease in mean serum TSH levels across estimated GFR deciles (range, 6.74 to $2.02 \mathrm{mIU} / \mathrm{L} ; P<0.0001$ ) in the whole population (data not shown).

In our study, the prevalence of thyroid abnormalities were found to be more in stage $\mathrm{V}$ suggesting an increased prevalence as the stage of CKD advances (Table 2).

Based on chi-square test, there is a statistically significant difference in the prevalence of subclinical hypothyroidism among CKD patients when compared with the general population (Table 3). Student's unpaired $t$ test between two different quantitative variables will suggest the significance between them. On Comparison of cases and controls, a statistically significant difference in their TSH, eGFR, urea and creatinine values except free $\mathrm{T}_{4}$ values exists suggesting that TSH, eGFR, Urea and Creatinine levels are higher than the controls except the free $\mathrm{T}_{4}$ values which are mostly comparable between cases and controls (Table 4).

Student's unpaired ' $t$ ' test between quantitative variables among cases suggests that TSH, eGFR, Urea and Creatinine levels are dependent on each other but the free $\mathrm{T}_{4}$ values are independent of these variables among CKD patients(Table 5).

Pearson's Correlation coefficient of TSH, free $\mathrm{T}_{4}$, Urea, Creatinine and eGFR values was studied among CKD patients (Table 6). There is a negative correlation between TSH and eGFR values suggesting that there was an inverse relationship between estimated GFR and TSH levels throughout the TSH range (Graph 1).

There is a positive correlation between free $\mathrm{T}_{4}$ and eGFR values among CKD patients suggesting that fall in free $\mathrm{T}_{4}$ occurs as the eGFR falls (Graph 2).

\section{Discussion}

In this small cohort of adult outpatients, we found an increased prevalence of subclinical primary hypothyroidism in persons with reduced estimated GFR independent of age, gender, fasting plasma glucose, total cholesterol, serum albumin and triglyceride concentrations. Moreover, with progressively lower estimated GFR, there was a graded increased likelihood of subclinical primary hypothyroidism. Accordingly, there was a significant inverse association between estimated GFR and TSH levels throughout the normal and high TSH ranges. It has been estimated that the prevalence of subclinical primary hypothyroidism ranges between $4 \%$ and $10 \%$ in the general population (12-14) and between $7 \%$ and $26 \%$ in the elderly (15-17). Previous studies have reported a higher prevalence of goiter and/or thyroid hormone abnormalities in persons with end-stage renal disease $(18-22)$. In addition, some of these studies suggest that abnormal thyroid hormone levels (i.e., low plasma free triiodothyronine with normal TSH levels as typically seen in the low T3 syndrome) in patients requiring chronic dialysis are independent predictors of all-cause and cardiovascular mortality (20 -22), likely because of an association with underlying chronic inflammation $(19,22)$. Although numerous contributing factors have been hypothesized, including altered iodine metabolism, decreased peripheral sensitivity to hormones, and autoimmune thyroiditis, the exact underlying mechanisms linking advanced CKD and primary thyroid dysfunction remain unclear. Conversely, in clinically overt primary hypothyroidism (myxedema), the most significant manifestation of changes in renal function is hyponatremia, which results from an impairment in renal diluting capacity leading to water retention (23). Moreover, clinically overt hypothyroidism may also cause renal hemodynamic alterations produced by a decreased cardiac output, which lead to a progressive decline in GFR.Lo et al. recently noticed that the prevalence of subclinical and clinical primary hypothyroidism increased with progressively lower levels of kidney function in a nationally representative cohort of U.S. adults (10). Among these participants, more than $20 \%$ of those with an estimated GFR $<60 \mathrm{ml} / \mathrm{min}$ per $1.73 \mathrm{~m} 2 \mathrm{had}$ clinical or subclinical primary hypothyroidism after controlling for age, gender, and race/ethnicity (10). A study by Michel Chonchol and his colleagues in a cohort of 3089 adult patients extends these previous observations by demonstrating a high prevalence of subclinical primary hypothyroidism (18\%) in a large non-U.S. cohort of persons with CKD not requiring chronic dialysis that is independent of important confounding factors. (24) Subclinical primary hypothyroidism is most commonly caused by chronic autoimmune thyroiditis, which is typically characterized by a mild asymptomatic goiter with diffuse hypoechogenicity on thyroid ultrasound and by the presence of a high titer of serum thyroid autoantibodies (25). Other less common causes of transient or permanent primary hypothyroidism include drug-induced hypothyroidism, subacute thyroiditis, radiation thyroiditis, and postpartum thyroiditis (26). However, independent of its specific etiology, several studies have shown that subclinical primary hypothyroidism may affect both diastolic and systolic cardiac function, worsen traditional risk factors for cardiovascular disease, including blood pressure, plasma lipid profile, and endothelial function $(5-8,27)$. This study has several limitations that should be noted. First, because this study is crosssectional, the present analysis is limited in its ability to establish causal or temporal relationships between subclinical primary hypothyroidism and kidney disease. Second, the definition of kidney function was based on estimated GFR rather than on more precise measurement of kidney function, such as iothalamate clearance. Third, nonthyroidal (e.g., low T3 syndrome, which is typically seen in some ill patients, including those with end-stage renal disease) and thyroidal (as reported above) causes of subclinical hypothyroidism were not 
identified. Finally, the sample size is very small to make any strong statements. Notwithstanding these possible limitations, this analysis has several strengths. First, our clinical laboratory used uniform methods to collect data on serum TSH and FT4 concentrations. Second, subclinical primary hypothyroidism was diagnosed according to widely accepted diagnostic criteria.

\section{Conclusion}

Subclinical primary hypothyroidism is more common in persons with CKD not requiring dialysis compared with those with normal kidney function in a small sample of outpatient adults. And the prevalence of subclinical hypothyroidism increases with the increase in the stage of chronic kidney disease. Future clinical and experimental studies should explore potential causal mechanisms linking subclinical primary hypothyroidism and CKD. The possible adverse effects of subclinical hypothyroidism on cardiovascular risk associated with CKD are presently unknown. Whether adult patients with CKD should be routinely screened for subclinical primary hypothyroidism requires further investigation.

Thyroid Abnormalities in Cases Vs Controls (Table 1)

\begin{tabular}{|l|l|l|l|l|}
\hline \multirow{2}{*}{} & Cases & Controls & \% \\
\cline { 2 - 5 } & No. & $\%$ & No. & 98 \\
\hline Normal & 17 & 34 & 49 & 2 \\
\hline Subclinical Hypothyroidism & 30 & 60 & 1 & 0 \\
\hline Hypothyroidism & 2 & 4 & 0 & 0 \\
\hline Subclinical Hyperthyroidism & 1 & 2 & 0 & 0 \\
\hline Hyperthyroidism & 0 & 0 & 0 & 0 \\
\hline Total & 50 & 100 & 50 & 100 \\
\hline
\end{tabular}

Thyroid disorders in different stages of CKD: (Table 2)

\begin{tabular}{|l|l|l|l|l|}
\hline & Stage II & Stage III & Stage IV & Stage V \\
\hline Normal & 2 & 3 & 11 & 1 \\
\hline Subclinical hypothyroidism & 4 & 5 & 12 & 9 \\
\hline Hypothyroidism & 0 & 0 & 2 & 0 \\
\hline Hyperthyroidism & 0 & 0 & 0 & 0 \\
\hline Subclinical Hyperthyroidism & 0 & 0 & 1 & 0 \\
\hline Thyroid abnormalities & 4 out of 6 (66.6\%) & 5 out of 8 (62.5\%) & 12 out of 26 (46\%) & 9 out of $10(90 \%)$ \\
\hline
\end{tabular}

Chi-square test for thyroid abnormalities among cases and controls(Table 3)

\begin{tabular}{|l|l|l|l|}
\hline \multicolumn{1}{|c|}{ abnormalities (SCH, } & Cases & Controls & Total \\
\hline $\begin{array}{l}\text { Thyroid } \\
\text { Hypothyroidism, etc.) }\end{array}$ & 33 & 1 & 34 \\
\hline Normal thyroid function & 17 & 49 & 66 \\
\hline Total & 50 & 50 & 100 \\
\hline
\end{tabular}

Calculated $\chi^{2}$ value $=45.63 \mathrm{p}<0.05$

't' test of different analytes between Cases \& Controls(Table 4)

\begin{tabular}{|l|l|l|l|}
\hline $\begin{array}{l}\text { S. } \\
\text { No. }\end{array}$ & Analytes & $\begin{array}{l}\text { 't' values } \\
\text { Cases Vs Controls }\end{array}$ & Significance \\
\hline 1. & TSH & 1.2 & $<0.001^{*}$ \\
\hline 2. & Free $\mathrm{T}_{4}$ & 9.2 & $>0.001$ \\
\hline 3. & Urea & 0.0003 & $<0.001^{*}$ \\
\hline 4. & Creatinine & 0.236 & $<0.001^{*}$ \\
\hline 5. & 0.8622 & $<0.001^{*}$ \\
\hline
\end{tabular}

Unpaired ' $t$ ' tests between different analytes among CKD patients (Table 5)

\begin{tabular}{|l|l|l|l|}
\hline S.No. & Analytes & 't' values & Significance \\
\hline 1. & TSH Vs eGFR & 0.47 & $<0.001^{*}$ \\
\hline 2. & TSH Vs Urea & 0.24 & $<0.001^{*}$ \\
\hline 3. & Free T4 Vs eGFR & 0.65 & $<0.001^{*}$ \\
\hline 4. & Free $\mathrm{T}_{4}$ Vs creatinine & 2.0 & $<0.001^{*}$ \\
\hline 5. & Free $\mathrm{T}_{4}$ Vs Urea & 1.25 & $<0.001^{*}$ \\
\hline
\end{tabular}

* - statistically significant

Pearson's Correlation between different analytes in CKD patients (Table 6)

\begin{tabular}{|l|l|l|l|}
\hline S. No. & Analytes & Pearson's correlation coefficient & Significance \\
\hline 1. & TSH Vs eGFR & -0.054 & Negative correlation \\
\hline 2. & TSH Vs Urea & 0.0211 & Positive correlation \\
\hline 3. & Free $\mathrm{T}_{4}$ Vs eGFR & 0.282 & Positive correlation \\
\hline 4. & Free $\mathrm{T}_{4}$ Vs Urea & -0.075 & Negative correlation \\
\hline 5. & Free $\mathrm{T}_{4}$ Vs creatinine & -0.195 & Negative correlation \\
\hline
\end{tabular}


Graph 1

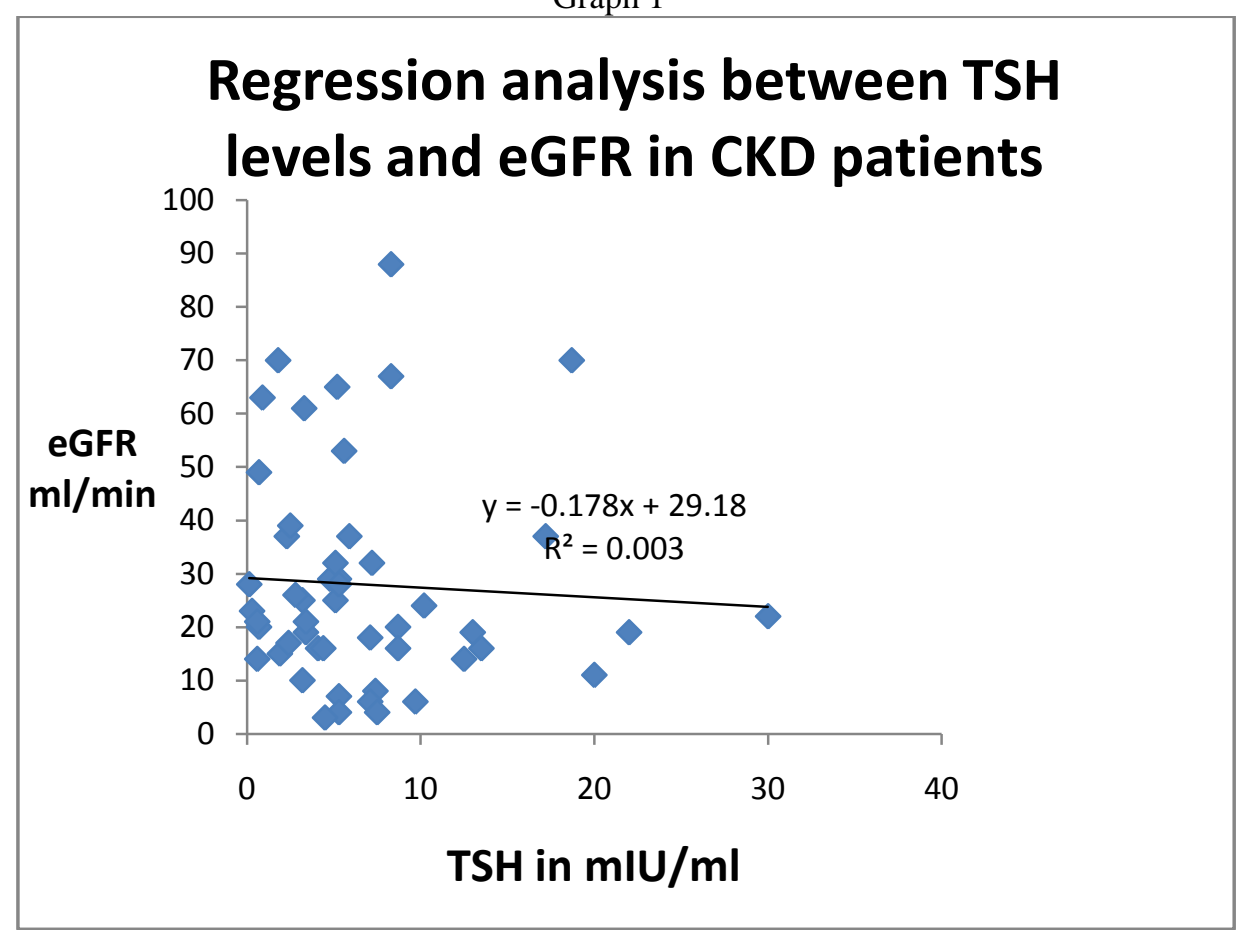

R Value : 0.056

Graph 2

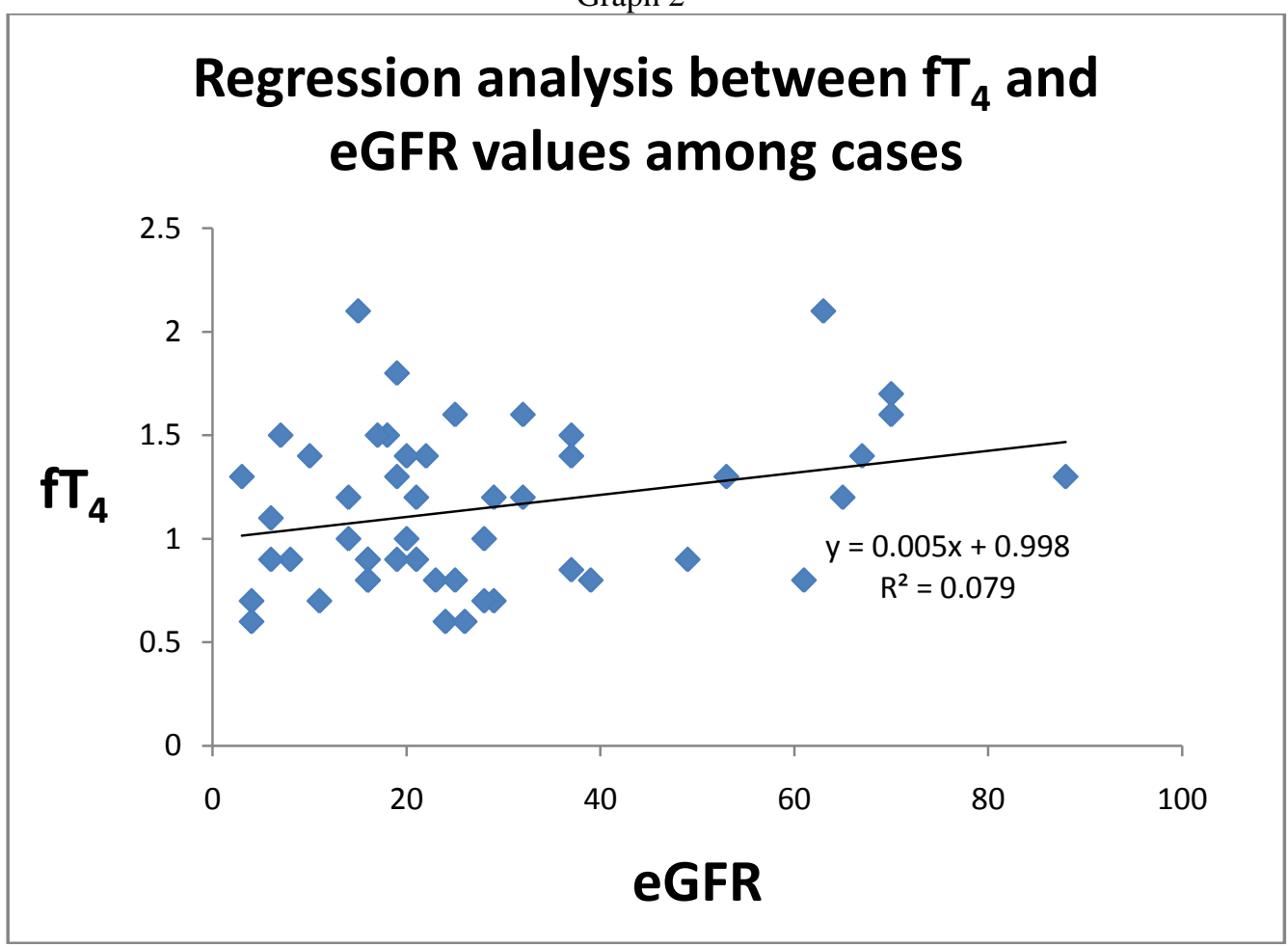

$R$ value : 0.3 


\section{References}

[1]. Hamilton TE, Davis S, Onstad L, Kopecky KJ: Thyrotropin levels in a population with no clinical, autoantibody, or ultrasonographic evidence of thyroid disease: implications for the diagnosis of subclinical hypothyroidism. J Clin Endocrinol Metab 93: 1224-1230, 2008.

[2]. Biondi B, Cooper DS: The clinical significance of subclinical thyroid dysfunction. Endocr Rev 29: 76-131, 2008.

[3]. Surks MI, Ortiz E, Daniels GH, Sawin CT, Col NF, Cobin RH, Franklyn JA, Hershman JM, Burman KD, Denke MA, Gorman C, Cooper RS, Weissman NJ: Subclinical thyroid disease: scientific review and guidelines for diagnosis and management. JAMA 291: 228-238, 2004 .

[4]. Duntas LH, Wartofsky L: Cardiovascular risk and subclinical hypothyroidism: focus on lipids and new emerging risk factors. What is the evidence? Thyroid 17: 1075-1084, 2007.

[5]. Iervasi G, Molinaro S, Landi P, Taddei MC, Galli E, Mariani F, L'Abbate A, Pingitore A: Association between increased mortality and mild thyroid dysfunction in cardiac patients. Arch Intern Med 167: 1526-1532, 2007.

[6]. Rodondi N, Newman AB, Vittinghoff E, de Rekeneire N, Satterfield S, Harris TB, Bauer DC: Subclinical hypothyroidism and the risk of heart failure, other cardiovascular events, and death. Arch Intern Med 165: 2460-2466, 2005.

[7]. Walsh JP, Bremner AP, Bulsara MK, O'Leary P, Leedman PJ, Feddema P, Michelangeli V: Subclinical thyroid dysfunction as a risk factor for cardiovascular disease. Arch Intern Med 165: 467-2472, 2005

[8]. Enia G, Panuccio V, Cutrupi S, Pizzini P, Tripepi G, Mallamaci F, Zoccali C: Subclinical hypothyroidism is linked to microinflammation and predicts death in continuous ambulatory peritoneal dialysis. Nephrol Dial Transplant 22: 538-544, 2007

[9]. Chen HS, Wu TE, Jap TS, Lu RA, Wang ML, Chen RL, Lin HD: Subclinical hypothyroidism is a risk factor for nephropathy and cardiovascular diseases in type 2 diabetic patients. Diabet Med 24: 1336-1344, 2007

[10]. Lo JC, Chertow GM, Go AS, Hsu CY: Increased prevalence of subclinical and clinical hypothyroidism in persons with chronic kidney disease. Kidney Int 67: 1047-1052, 2005

[11]. Kidney Disease Outcomes Quality Initiative. Clinical practice guidelines for bone metabolism and disease in chronic kidney disease. Am J Kidney Dis 42[Suppl 3]: 1-201, 2003

[12]. Canaris GJ, Manowitz NR, Mayor G, Ridgway EC: The Colorado Thyroid Disease Prevalence Study. Arch Intern Med 160: 526534, 2000

[13]. Tunbridge WM, Evered DC, Hall R, Appleton D, Brewis M, Clark F, Evans JG, Young E, Bird T, Smith PA: The spectrum of thyroid disease in a community: the Whickham survey. Clin Endocrinol (Oxf) 7: 481-493, 1977

[14]. Schectman JM, Kallenberg GA, Shumacher RJ, Hirsch RP: Yield of hypothyroidism in symptomatic primary care patients. Arch Intern Med 149: 861-864, 1989

[15]. Helfand M, Crapo LM: Screening for thyroid disease. Ann Intern Med 112: 840-849, 1990

[16]. Bagchi N, Brown TR, Parish RF: Thyroid dysfunction in adults over age 55 years: a study in an urban U.S. community. Arch Intern Med 150: 785-787, 1990

[17]. Sawin CT, Chopra D, Azizi F, Mannix JE, Bacharach P: The aging thyroid. Increased prevalence of elevated serum thyrotropin levels in the elderly. JAMA 242: 247-250, 1979

[18]. Lim VS: Thyroid function in patients with chronic renal failure. Am J Kidney Dis 38[Suppl 1]: 80-84, 2001

[19]. Zoccali C, Tripepi G, Cutrupi S, Pizzini P, Mallamaci F: Low triiodothyronine: a new facet of inflammation in endstage renal disease. J Am Soc Nephrol 16: 2789-2795, 2005

[20]. Zoccali C, Benedetto F, Mallamaci F, Tripepi G, Cutrupi S, Pizzini P, Malatino LS, Bonanno G, Seminara G: Low triiodothyronine and cardiomyopathy in patients with endstage renal disease. J Hypertens 24: 2039-2046, 2006

[21]. Zoccali C, Mallamaci F, Tripepi G, Cutrupi S, Pizzini P: Low triiodothyronine and survival in end-stage renal disease. Kidney Int 70: 523-528, 2006

[22]. Carrero JJ, Qureshi AR, Axelsson J, Yilmaz MI, Rehnmark S, Witt MR, Ba'́rány P, Heimburger O, Suliman ME, Alvestrand A, Lindholm B, Stenvinkel P: Clinical and biochemical implications of low thyroid hormone levels (total and free forms) in euthyroid patients with chronic kidney disease. J Intern Med 262: 690-701, 2007

[23]. Bradley SE, Ste'phan F, Coelho JB, Re'ville P: The thyroid and the kidney. Kidney Int 6: 346-365, 1974

[24]. Michel Chonchol, Giuseppe Lippi, Gianluca Salvagno, Giacomo Zoppini,Michele Muggeo, and Giovanni Targher: Prevalence of Subclinical Hypothyroidism in Patients with Chronic Kidney Disease. Clin J Am Soc Nephrol. 2008 Sep; 3(5): $1296-1300$.

[25]. Hollowell JG, Staehling NW, Flanders WD, Hannon WH, Gunter EW, Spencer CA, Braverman LE: Serum TSH, T(4), and thyroid antibodies in the United States population (1988 to 1994): National Health and Nutrition Examination Survey (NHANES III). J Clin Endocrinol Metab 87: 489-499, 2002

[26]. Papi G, Uberti ED, Betterle C, Carani C, Pearce EN, Braverman LE, Roti E: Subclinical hypothyroidism. Curr Opin Endocrinol Diabetes Obes 14: 197-208, 2007

[27]. Ripoli A, Pingitore A, Favilli B, Bottoni A, Turchi S, Osman NF, De Marchi D, Lombardi M, L'Abbate A, Iervasi G: Does subclinical hypothyroidism affect cardiac pump performance? Evidence from a magnetic resonance imaging study. J Am Coll Cardiol 45: 439-445, 2005. 